\title{
Comment on: Progression of Hiatal Hernia
}

\author{
Gregory L. Falk ${ }^{1,2,3} \cdot$ Suzanna C. Gooley ${ }^{3}$
}

Received: 27 July 2021 / Accepted: 2 August 2021 / Published online: 11 August 2021

(c) The Society for Surgery of the Alimentary Tract 2021

Comment on: Progression of hiatal hernias [1]

Thank you for this very excellent communication. Those of us who work extensively in this area have long recognised the phenomenon of the historically enlarging hiatus hernia, with little documented supporting evidence. It is nice some are now available. Many patients describe having a small hiatus hernia with typical reflux symptoms of heartburn and regurgitation which over many decades goes on to become entrapment symptoms (dysphagia, early satiety, post-prandial chest discomfort) as the hernia has become larger, often seen on serial barium meal over years.

It has been evident during surgical management of these patients that the diaphragmatic defect is most commonly anterior, the pericardium being visualised behind the larger anterior crural defect as soon as the sack is reduced. This is not the situation with the smaller hernia where the pericardium is not exposed on dissecting the hiatus. This has led me to develop the concept of failure of the central tendon of the diaphragm and movement of the left crural pillar laterally. During repair, the left hemi diaphragm is transposed towards the midline and flattens the dome of the left diaphragm and is part of a very useful technique of closure of the difficult hiatal defect [2]. There is a possible association with connective tissue deficiency $[3,4]$

Previous communication commenting on: Csucska, M., et al., Progression of Hiatal Hernias. Journal of Gastrointestinal Surgery, 2021. 25(3): p. 818-820.

Gregory L. Falk

sydney.heartburn@gmail.com

1 Chair Department Upper Gastro -Intestinal Surgery, Concord Repatriation General Hospital, Sydney, NSW, Australia

2 University of Sydney, Sydney, Australia

3 Sydney Heartburn Clinic, Suite 29/12 Tryon Road, Lindfield, NSW, Australia
These findings are congruent with the concept of the enlarging hiatus over time, further evidence that the large mixed para-oesophageal hernia is a later stage of hiatal herniation.

\section{Declarations}

Conflict of Interest The authors declare no competing interests.

\section{References}

1. 1.Csucska, M., et al., Progression of Hiatal Hernias. Journal of Gastrointestinal Surgery, 2021. 25(3): p. 818-820.

2. Falk, G.L., D'Netto, T.J., Little, S.C. Giant hiatus hernia: closure of the difficult hiatus. European Surgery, 2019. 51: p.291-294

3. 3.Curci, J.A., et al., Elastic fiber depletion in the supporting ligaments of the gastroesophageal junction: a structural basis for the development of hiatal hernia. J Am Coll Surg, 2008. 207(2): p. 191-6.

4. 4.Åsling, B., et al., Collagen type III alpha I is a gastro-oesophageal reflux disease susceptibility gene and a male risk factor for hiatus hernia. Gut, 2009. 58(8): p. 1063.

Publisher's Note Springer Nature remains neutral with regard to jurisdictional claims in published maps and institutional affiliations. 